\title{
Marker compounds contents of Salvia miltiorrhiza Radix depending on the cultivation regions
}

\author{
Gi-Un Seong ${ }^{1} \cdot$ Mi-Yeon Kim² ${ }^{2}$ Shin-Kyo Chung ${ }^{1}$
}

Received: 25 February 2019 / Accepted: 19 March 2019 / Published Online: 30 June 2019

(C) The Korean Society for Applied Biological Chemistry 2019

\begin{abstract}
Salvia miltiorrhiza Radix is cultivated in Korea and China and is traditionally used to treat cardiovascular diseases. In this study, we developed and validated a quantitative analysis method for S. miltiorrhiza Radix using high-performance liquid chromatography (HPLC). Identification was performed using ultra performance liquid chromatography-tandem mass spectrometry. For quantitative analysis, we used seven marker compounds. Separation conditions for HPLC were optimized using an ODS column with gradient conditions of $1 \%$ formic acid in distilled water and $1 \%$ formic acid in acetonitrile, with a flow rate of 0.8 $\mathrm{mL} / \mathrm{min}$ and a detection wavelength of $280 \mathrm{~nm}$. This method showed good linearity $\left(\mathrm{R}^{2}=0.9998\right)$, precision (relative standard deviation $\leq 3.3 \%$ ), accuracy (recovery of $94.16-102.89 \%$ ), limit of detection $(7.53 \mu \mathrm{g} / \mathrm{mL})$, and limit of quantification $(23.71 \mu \mathrm{g} / \mathrm{mL})$. This approach successfully quantified marker compounds in $S$. miltiorrhiza Radix. The individual marker compounds were identified by comparing the molecular masses and retention times with does standard compounds. Marker compound contents of $S$. miltiorrhiza Radix were investigated with different cultivation regions. Seven marker compounds were detected and quantified in all samples. Among them, salvianolic acid B showed the highest contents and it ranged from 4.13 to $7.15 \%$. The salvianolic acid B content $(7.15 \%)$ of marker compound was the highest in Bonghwa, and the tanshinone IIA content $(1.90 \%)$ was the highest in Pohang. The results of marker compounds and developed
\end{abstract}

Shin-Kyo Chung $(\bowtie)$

E-mail:kchung@knu.ac.kr

${ }^{1}$ School of Food Science and Biotechnology, Kyungpook National University, Daegu 41566, Republic of Korea

${ }^{2}$ KMF Co., Ltd., Daegu 41065, Republic of Korea

This is an Open Access article distributed under the terms of the Creative Commons Attribution Non-Commercial License (http://creativecommons. org/licenses/by-nc/3.0/) which permits unrestricted non-commercial use, distribution, and reproduction in any medium, provided the original work is properly cited. method were intended to provide a favorable reference for the study of $S$. miltiorrhiza Radix from different regions of Korea.

Keywords Cultivation region · High-performance liquid chromatography · Liquid chromatography-mass spectrometry · Salvia miltiorrhiza Radix $\cdot$ Salvianolic acid B · Tanshinone IIA

\section{Introduction}

Salvia miltiorrhiza Radix is cultivated in China and Korea [1] and is used as a traditional medicine to treat coronary, cerebrovascular diseases, hepatitis, cardiovascular diseases, and chronic renal failure [2,3]. Its various biological effects, including inhibition of lipid peroxidation, and anticancer, antioxidant, antimicrobial, and immune activities, have also been studied and reported [4-7]. These biological effects have been found to be mainly caused by marker compounds including hydrophilic phenolic acids and lipophilic diterpenes [8-10]. For quality control in its medicinal products, salvianolic acid B, tanshinone IIA, cryptotanshinone, and tanshinone I have been selected as chemical markers by the Chinese Pharmacopoeia. Salvianolic acid B has also been selected as a chemical marker by the Korean Pharmacopoeia. Therefore, since rapid and repeatable quantification of salvianolic acid B and tanshinone IIA contents are essential for evaluating quality, a suitable analysis method is required. Several analytical methods have been used to analyze $S$. miltiorrhiza Radix and its products [11-13]. Most plants contain different marker compounds whose activities depend on the variety, plant part, growth time, harvest time, and production region [14-16]. In this study, an HPLC approach was developed and validated for quantifying marker compounds, which were then identified using ultra performance liquid chromatography-tandem mass spectrometry (UPLC-MS). We also investigated geographical differences in these marker compounds occurring in S. miltiorrhiza sourced from different cultivation regions. 


\section{Materials and Methods}

\section{Chemicals and materials}

S. miltiorrhizae Radix were collected from different regions in Korea well-known for their cultivation of medicinal plants: Bonghwa (K-1), Gochang (K-2), Jangheung (K-3), Pohang (K-4), and Yeongyang (K-5). A Chinese-originating sample of $S$. miltiorrhizae Radix was purchased from a traditional medicine local market in Daegu, Korea. Standard compounds were purchased from Sigma-Aldrich (St. Louis, MO, USA). Water was triply distilled. HPLC grade acetonitrile was obtained from J.T. Baker (Phillipsburg, NJ, USA). All other reagents and solvents were of analytical grade.

\section{Sample preparation and HPLC analytical conditions}

S. miltiorrhizae Radix was dried at room temperature in the shade, then pulverized and sieved to the powder using $>60 \mu \mathrm{m}$ mesh. To prepare samples for analysis, $0.3 \mathrm{~g}$ of powder was sonicated with $50 \mathrm{~mL}$ of $75 \%$ ethanol for $30 \mathrm{~min}$ and filtered through a $0.45 \mu \mathrm{m}$ filter. We used an HPLC system (Waters Corp., Milford, MA, USA) with an ODS H80 analytical column $(4.6 \times 250 \mathrm{~mm}$ ID, $4 \mu \mathrm{m}$, YMC Co., Kyoto, Japan). The mobile phases consisted of distilled water (solvent A) and acetonitrile (solvent B), both containing $1 \%$ formic acid $(\mathrm{v} / \mathrm{v})$. Gradient elution for HPLC analysis was conducted for chromatographic separation, using gradient programs of $0.00-10.00 \mathrm{~min}, 25-25 \% \mathrm{~B} ; 10.00-20.00$ $\min , 25-60 \% \mathrm{~B} ; 20.00-25.00 \mathrm{~min}, 60-85 \% \mathrm{~B}$; and $25.00-40.00$ min, $85-85 \%$ B. Flow rate was $0.8 \mathrm{~mL} / \mathrm{min}$, with detection wavelength at $280 \mathrm{~nm}$, and injection volume of $10 \mu \mathrm{L}$. Marker compounds of the sample were identified by comparing their retention times with those of standards. Compounds were tentatively quantified on the basis of dry weight using the linear regression equation obtained from the standard calibration curves.

\section{HPLC analytical method validations of marker compounds}

Validation was carried out according to internationally accepted criteria [17]. The parameters evaluated were system suitability, selectivity, linearity, precision and accuracy, limits of detection and quantification, and system suitability [18]. The linearity of the marker compounds was determined using external standards. Reference solutions of salvianolic acid B at concentrations of 25$400 \mu \mathrm{g} / \mathrm{mL}$, salvianolic acid A at concentrations of 50-200 $\mu \mathrm{g} /$ $\mathrm{mL}$, and the other five compounds at concentrations of 25-200 $\mu \mathrm{g} /$ $\mathrm{mL}$ were analyzed under optimized chromatographic conditions. For each sample analyte, LOD and LOQ were defined as the lowest concentration that could be determined with a signal to noise ratio $(\mathrm{S} / \mathrm{N})$ of three. The accuracy of the proposed method was indicated by the percent recovery of the four different concentrations of marker compounds extracted from the prepared sample solution using a stock solution. The percent relative standard deviation was calculated as a measure of method precision. Accuracy and precision were determined by multiple analysis of samples prepared at different concentrations on a single day and different days $(n=3)$.

\section{Identification of marker compounds using UPLC-MS}

Marker compounds were identified using UPLC-MS-MS, consisting of a Waters UPLC system with a Waters Xevo TQ-S micro MS with electrospray ionization source. Chromatography was performed on an Acquity UPLC BEH ODS column $(2.1 \times 100 \mathrm{~mm}$ ID, 1.7 $\mu \mathrm{m})$. The mobile phase consisted of $0.1 \%$ formic acid in distilled water (solvent A) and acetonitrile (solvent B), with a flow rate of $0.392 \mathrm{~mL} / \mathrm{min}$ and an injection volume of $5 \mu \mathrm{L}$. The gradient elution for UPLC analysis was conducted for chromatographic separation, with gradient programs of $0.00-1.70 \mathrm{~min}, 25-25 \% \mathrm{~B}$; $1.70-3.40 \mathrm{~min}, 25-60 \% \mathrm{~B}$; $3.40-4.25 \mathrm{~min}, 60-85 \% \mathrm{~B}$; and $4.25-$ $6.80 \mathrm{~min}, 85-85 \% \mathrm{~B}$. The electrospray ionization interface was conducted both positive and negative modes.

\section{Statistical analysis}

Data are expressed as mean \pm standard deviation $(n=3)$. Duncan's multiple range tests with significance judged at $p<0.05$ were performed to determine significant differences between the means using SAS software (SAS, Inc., Cary, NC, USA).

\section{Results and Discussion}

\section{Validations of marker compounds in S. miltiorrhiza Radix using HPLC}

Retention times of marker compounds were 3.8, 10.6, 13.7, 18.9, 30.5, 30.8, and $33.9 \mathrm{~min}$ for salvianic acid A, rosmarinic acid, salvianolic acid B, salvianolic acid A, cryptotanshinone, tanshinone I, and tanshinone IIA, respectively (Fig. 1). Salvianic acid A, rosmarinic acid, salvianolic acid $\mathrm{B}$, and salvianolic acid A correspond to hydrophilic phenolic compounds, whereas tanshinone IIA, tanshinone I, and cryptotanshinone represent lipophilic diterpene compounds [19]. Therefore, all compounds in $S$. miltiorrhizae Radix have broad ranges of polarity [20]. Regression equations for linearity, LOD, and LOQ of the seven compounds were calculated based on the mean peak areas versus the standard concentrations (Table 1). Each coefficient of correlation $\left(\mathrm{R}^{2}\right)$ was $\geq 0.9998$, as determined by the least square analysis, suggesting good linearity. The LOD and LOQ of standard compounds were 2.56-7.83 and 7.76-23.71 $\mu \mathrm{g} / \mathrm{mL}$, respectively. Intra-day samples showed intra-day assay precision below $1.24 \%$ and accuracies ranging from 98.73 to $102.17 \%$ (Table 2). Inter-day samples showed precision below $3.30 \%$ and accuracies ranging from 94.16 to $102.89 \%$. Variations in precision were less than $3.3 \%$, and variations in accuracy ranged from 94.16 to $102.89 \%$. These results indicate that this HPLC method provides good accuracy, consistent with previous reports [12]. 




(B)

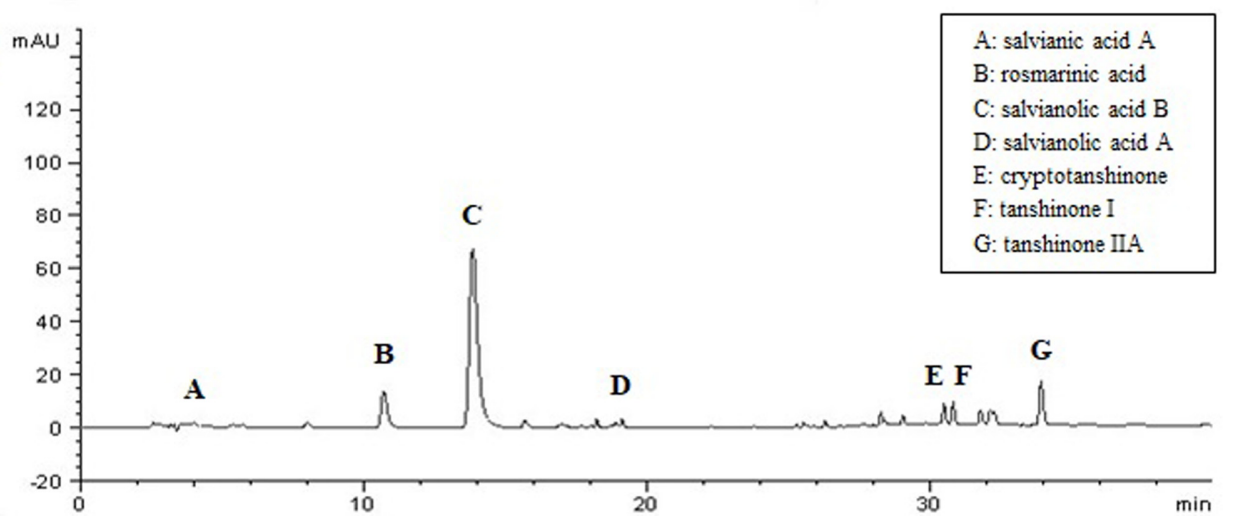

Fig. 1 HPLC chromatograms of standard compounds (A) and S. miltiorrhiza Radix extract (B)

Table 1 Linearity, LODs, and LOQs of marker compounds

\begin{tabular}{lccccc}
\hline \hline \multicolumn{1}{c}{ Compounds } & Regression equation & Correlation coefficient $\left(\mathrm{R}^{2}\right)$ & Linear range $(\mu \mathrm{g} / \mathrm{mL})$ & $\mathrm{LOD}(\mu \mathrm{g} / \mathrm{mL})$ & $\mathrm{LOQ}(\mu \mathrm{g} / \mathrm{mL})$ \\
\hline salvianic acid A & $\mathrm{Y}=3.9135 \mathrm{x}+11.417$ & 0.99995 & $25-200$ & 2.56 & 7.76 \\
rosmarinic acid & $\mathrm{Y}=8.8977 \mathrm{x}+13.407$ & 0.99986 & $25-200$ & 4.57 & 13.86 \\
salvianolic acid B & $\mathrm{Y}=5.0297 \mathrm{x}-24.748$ & 0.99980 & $25-400$ & 7.83 & 23.71 \\
salvianolic acid A & $\mathrm{Y}=3.2754 \mathrm{x}-2.85$ & 0.99987 & $50-200$ & 5.23 & 15.85 \\
cryptotanshinone & $\mathrm{Y}=13.219 \mathrm{x}-55.054$ & 0.99992 & $25-200$ & 3.42 & 10.37 \\
tanshinone I & $\mathrm{Y}=10.204 \mathrm{x}+48.804$ & 0.99981 & $25-200$ & 5.29 & 16.02 \\
tanshinone IIA & $\mathrm{Y}=7.1288 \mathrm{x}-26.053$ & 0.99991 & $25-200$ & 3.69 & 11.19 \\
\hline
\end{tabular}

${ }^{a} y=$ mean peak area; $x=$ concentration of the standard solution $(g / m L)$

\section{Identification of marker compounds in S. miltiorrhiza Radix using UPLC-MS}

Separated marker compounds of $S$. miltiorrhiza Radix were identified by comparison with standards using UPLC retentions time and mass spectra analyses (Table 3). The retention times of marker compounds were $0.83,1.64,1.93,3.89,5.78,5.80$, and 6.24 min for salvianic acid A, rosmarinic acid, salvianolic acid B, salvianolic acid A, cryptotanshinone, tanshinone I, and tanshinone IIA, respectively, which were the same as those of standards. Chemical structures and MS/MS spectra are shown in Fig. 2. The mass spectrum of marker compounds showed significant ions at $\mathrm{m} / \mathrm{z}$ values of $197.04,359.15,717.25,493.04,277.16,297.17$, and
295.23, which matched with the molecular weights of marker compounds, respectively [21].

For phenolic acid compounds, small molecules such as carbon dioxide, carbon monoxide, and water were produced by the monomers because of the presence of carboxyl, carbonyl, or hydroxyl groups [22]. Salvianic acid A showed as deprotonated molecules at $m / z$ 197.04. The fragment ions corresponded to CO and $\mathrm{H}_{2} \mathrm{O}$ loss from the parent ion. Rosmarinic acid showed as deprotonated molecules at $\mathrm{m} / \mathrm{z}$ 359.15. Fragment ions at $\mathrm{m} / \mathrm{z}$ 161.07 and 179.22 corresponded to salvianic acid A or caffeic acid loss from the parent ion. Salvianolic acid B showed as deprotonated molecules at $\mathrm{m} / \mathrm{z}$ 717.25 The fragment ions $\mathrm{m} / \mathrm{z}$ 
Table 2 Intra-day and inter-day precision (RSD, \%) and accuracy (recovery, \%) of marker compounds

\begin{tabular}{|c|c|c|c|c|c|}
\hline \multirow[b]{2}{*}{ compounds } & \multirow{2}{*}{$\begin{array}{c}\text { Concentration } \\
(\mathrm{g} / \mathrm{mL})\end{array}$} & \multicolumn{2}{|c|}{ Intra-day $(n=3)$} & \multicolumn{2}{|c|}{ Inter-day $(n=3)$} \\
\hline & & $\begin{array}{l}\text { precision } \\
(\mathrm{RSD}, \%)\end{array}$ & $\begin{array}{c}\text { accuracy } \\
\text { (recovery, \%) }\end{array}$ & $\begin{array}{l}\text { precision } \\
(\mathrm{RSD}, \%)\end{array}$ & $\begin{array}{c}\text { accuracy } \\
\text { (recovery, \%) }\end{array}$ \\
\hline \multirow{4}{*}{$\begin{array}{l}\text { salvianic } \\
\text { acid A }\end{array}$} & 200 & 1.01 & 100.29 & 1.27 & 99.47 \\
\hline & 100 & 0.68 & 99.14 & 1.44 & 99.87 \\
\hline & 50 & 1.16 & 99.65 & 1.91 & 100.48 \\
\hline & 25 & 1.24 & 99.58 & 3.30 & 97.85 \\
\hline \multirow{4}{*}{$\begin{array}{l}\text { rosmarinic } \\
\text { acid }\end{array}$} & 200 & 0.95 & 99.52 & 1.43 & 100.72 \\
\hline & 100 & 0.63 & 99.43 & 2.50 & 99.69 \\
\hline & 50 & 0.89 & 100.19 & 2.19 & 98.79 \\
\hline & 25 & 0.78 & 102.17 & 1.55 & 101.57 \\
\hline \multirow{5}{*}{$\begin{array}{l}\text { salvianolic } \\
\text { acid B }\end{array}$} & 400 & 0.93 & 99.78 & 1.37 & 101.91 \\
\hline & 200 & 0.92 & 99.83 & 1.31 & 101.87 \\
\hline & 100 & 0.43 & 100.51 & 0.86 & 102.89 \\
\hline & 50 & 0.75 & 100.72 & 1.64 & 102.72 \\
\hline & 25 & 0.62 & 100.19 & 1.08 & 99.87 \\
\hline \multirow{4}{*}{$\begin{array}{l}\text { salvianolic } \\
\text { acid A }\end{array}$} & 200 & 0.92 & 100.61 & 1.54 & 99.88 \\
\hline & 150 & 0.36 & 101.60 & 1.26 & 98.50 \\
\hline & 100 & 0.90 & 100.57 & 2.23 & 102.61 \\
\hline & 50 & 0.60 & 100.11 & 1.22 & 101.19 \\
\hline \multirow{4}{*}{$\begin{array}{l}\text { cryptotansh } \\
\text { inone }\end{array}$} & 200 & 0.41 & 101.35 & 1.41 & 99.53 \\
\hline & 100 & 0.48 & 100.26 & 1.49 & 99.28 \\
\hline & 50 & 0.15 & 100.34 & 1.50 & 95.56 \\
\hline & 25 & 0.19 & 100.20 & 0.52 & 94.16 \\
\hline \multirow{4}{*}{$\begin{array}{c}\text { tanshinone } \\
\text { I }\end{array}$} & 200 & 0.23 & 99.79 & 1.67 & 100.86 \\
\hline & 100 & 0.68 & 99.47 & 2.28 & 101.77 \\
\hline & 50 & 0.64 & 99.78 & 2.94 & 99.52 \\
\hline & 25 & 0.62 & 102.08 & 2.89 & 104.11 \\
\hline \multirow{4}{*}{$\begin{array}{l}\text { tanshinone } \\
\text { IIA }\end{array}$} & 200 & 0.39 & 99.71 & 2.39 & 97.04 \\
\hline & 100 & 0.31 & 98.73 & 2.30 & 101.15 \\
\hline & 50 & 0.95 & 100.59 & 1.62 & 98.67 \\
\hline & 25 & 0.26 & 99.61 & 2.64 & 101.00 \\
\hline
\end{tabular}

321.15 and 519.13 corresponded to one or two ionized molecules of salvianic acid A $(\mathrm{m} / \mathrm{z} 198,198 \times 2)$ loss from the parent ion. Salvianolic acid A showed as deprotonated molecules at $\mathrm{m} / \mathrm{z}$
493.04. Fragment ions at $m / z 295.22$ were formed by the loss of salvianic acid A $(\mathrm{m} / \mathrm{z}$ 198) from the parent ion. Tanshinone I showed as protonated molecules at $\mathrm{m} / \mathrm{z}$ 277.16. The primary fragment ions at $\mathrm{m} / \mathrm{z} 249.17$ corresponded to CO loss from the parent ion. Fragment ions at $\mathrm{m} / \mathrm{z} 221.17$ and 234.23 were formed by the losses of $\mathrm{CO}$ and $\mathrm{CH}_{3}$ from the parent ion. Cryptotanshinone showed as protonated molecules at $\mathrm{m} / \mathrm{z} 297.17$. The primary fragment ion at $m / z 254.30$ corresponded to $\mathrm{CO}$ and $\mathrm{CH}_{3}$ loss from the parent ion. Other fragment ions at $\mathrm{m} / \mathrm{z} 251.24$, 268.24, and 282.12 were formed by the losses of $\mathrm{CO}, \mathrm{CH}_{3}$, and $\mathrm{H}_{2} \mathrm{O}$ from the parent ion. Tanshinone IIA showed as protonated molecules at $m / z 295.23$. The primary fragment ion of tanshinone IIA at $m / z 206.23$ corresponded to $\mathrm{H}_{2} \mathrm{O}, \mathrm{CO}$, and $\mathrm{CH}_{3}$ loss from the parent ion. Secondary fragment ions at $\mathrm{m} / \mathrm{z} 234.11,249.30$, 262.18, and 277.31 were formed by the losses of $\mathrm{CO}, \mathrm{CH}_{3}$, and $\mathrm{H}_{2} \mathrm{O}$ from the parent ion. Based on these fragmental patterns and comparison with reference standards and literature data [23,24], the marker compounds could be identified using this method.

\section{Contents of marker compounds in S. miltiorrhiza Radix from different cultivation regions}

The marker compound contents of $S$. miltiorrhiza Radix from different cultivation regions were calculated using regression equations (Table 4). Marker compounds were detected and quantified in the samples. The contents of salvianic acid A, rosmarinic acid, salvianolic acid B, salvianolic acid A, cryptotanshinone, tanshinone I, and tanshinone IIA contents were 0.00 $0.03,0.24-0.55,4.13-7.15,0.04-0.13,0.07-0.57,0.00-0.47$, and $0.14-1.90 \%$, respectively. High contents of salvianolic acid B were detected in all samples, with the K-1 sample (7.15\%) containing the most. The salvianolic acid B content of $S$. miltiorrhiza Radix from different cultivation regions in Korea (5.53\%) was higher than that of the Chinese samples (4.42\%). Tanshinone IIA, tanshinone I, and cryptotanshinone contents were also higher in the Korean samples than in the Chinese samples $(p<0.05)$. Salvianolic acid A, which is one of the marker compounds of S. miltiorrhiza Radix, was not detected in this study; ordinarily, its content is low, though it can be converted from salvianolic acid B under high temperature and pressure [25-

Table 3 Identification of marker compounds in S. miltiorrhiza Radix samples by ultra-performance liquid chromatography-tandem mass spectrometry (UPLC-MS-MS) analysis

\begin{tabular}{|c|c|c|c|c|}
\hline \multirow{2}{*}{ Compounds } & \multirow{2}{*}{ Retention time (min) } & \multirow{2}{*}{$\begin{array}{c}\text { Masses of }[\mathrm{M}-\mathrm{H}]^{-} \text {or } \\
{[\mathrm{M}+\mathrm{H}]^{+}(\mathrm{m} / \mathrm{z})}\end{array}$} & \multicolumn{2}{|c|}{ Fragmentation of ions $(\mathrm{m} / \mathrm{z})$} \\
\hline & & & ESI (-) & $\operatorname{ESI}(+)$ \\
\hline salvianic acid $\mathrm{A}$ & 0.83 & 197 & 179,135 & \\
\hline rosmarinic acid & 1.64 & 359 & $197,179,161$ & \\
\hline salvianolic acid B & 1.93 & 717 & $717,519,321$ & \\
\hline salvianolic acid A & 3.89 & 493 & 493,295 & \\
\hline tanshinone I & 5.78 & 277 & & $249,234,221$ \\
\hline cryptotanshinone & 5.80 & 297 & & $282,268,254,251$ \\
\hline tanshinone IIA & 6.24 & 295 & & $295,277,262,249,234,206$ \\
\hline
\end{tabular}


(A) salvianic acid $\mathrm{A}$

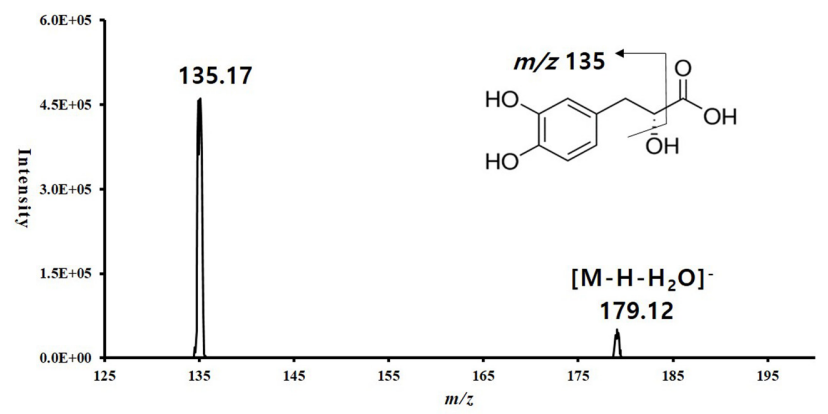

(C) salvianolic acid $B$



(E) tanshinone I

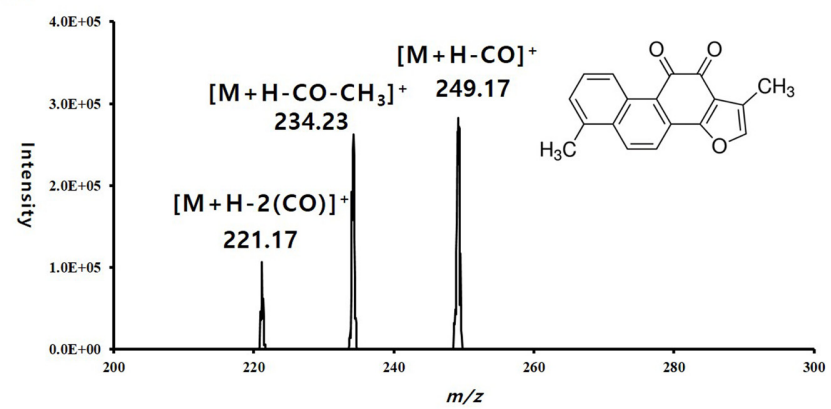

(B) rosmarinic acid

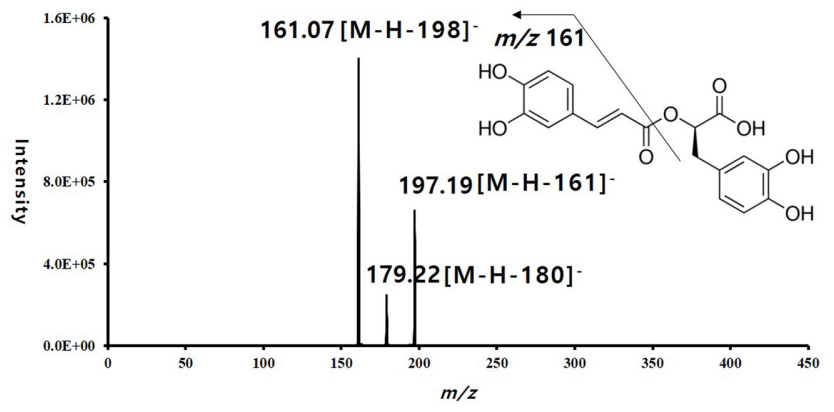

(D) salvianolic acid A

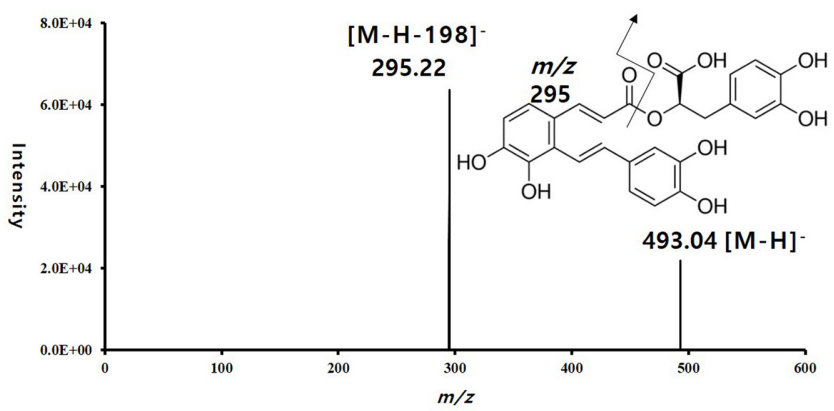

(F) cryptotanshinone

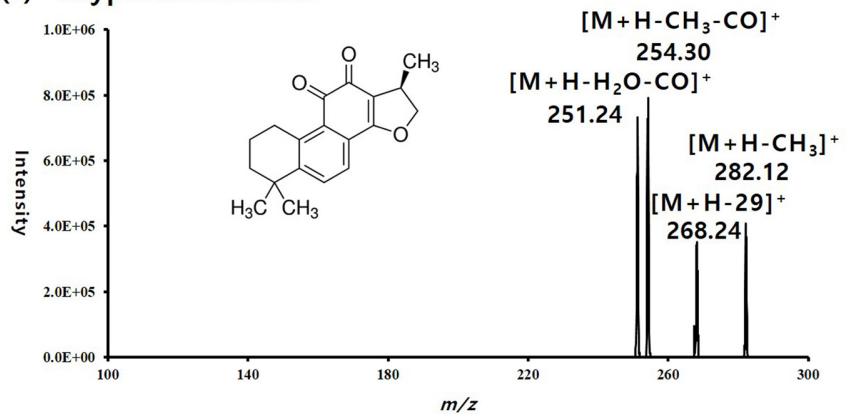

(G) tanshinone IIA

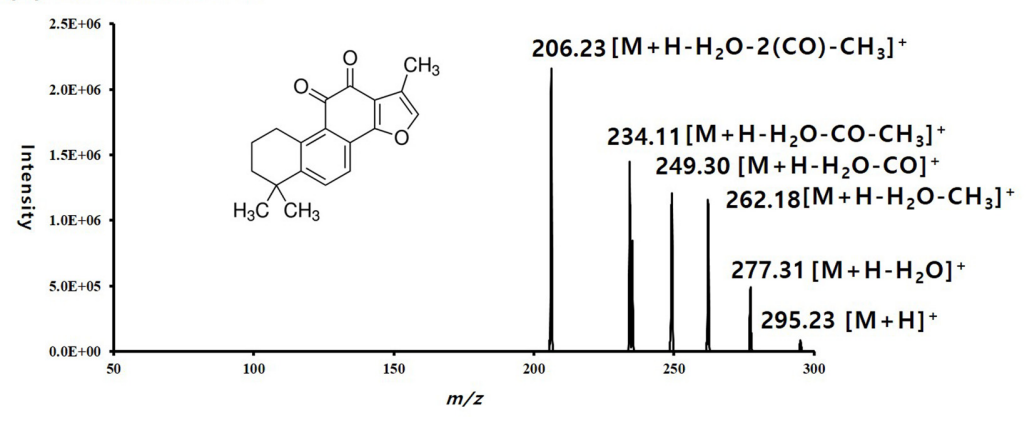

Fig. 2 Chemical structures and MS/MS spectra of marker compounds in S. miltiorrhiza Radix

27]. Other studies have also shown that salvianolic acid B shows the highest content compared to other marker compounds [28], accounting for $80-95 \%$ of the total contents. Overall, the contents quantified in this study were similar to or higher than those reported previously [29-31]. The present results enable quality control of traditional medicinal preparations containing $S$. miltiorrhiza and provide a reasonable strategy for developing novel functional food products. 
Table 4 Contents (dry weight basis, \%) of marker compounds in S. miltiorrhiza Radix depending on different cultivation regions

\begin{tabular}{|c|c|c|c|c|c|c|c|}
\hline Samples & salvianic acid $\mathrm{A}$ & rosmarinic acid & salvianolic acid B & salvianolic acid A & cryptotanshinone & tanshinone I & tanshinone IIA \\
\hline $\mathrm{K}-1^{\mathrm{a}}$ & $0.00 \pm 0.01^{\mathrm{C}}$ & $0.55 \pm 0.07^{\mathrm{A}}$ & $7.15 \pm 0.98^{\mathrm{A}}$ & $0.13 \pm 0.01^{\mathrm{A}}$ & $0.13 \pm 0.01^{\mathrm{BCD}}$ & $0.01 \pm 0.01^{\mathrm{C}}$ & $0.37 \pm 0.03^{\mathrm{CD}}$ \\
\hline $\mathrm{K}-2$ & $0.03 \pm 0.03^{\mathrm{A}}$ & $0.46 \pm 0.09^{\mathrm{AB}}$ & $5.88 \pm 1.11^{\mathrm{AB}}$ & $0.08 \pm 0.02^{\mathrm{ABC}}$ & $0.18 \pm 0.02^{\mathrm{B}}$ & $0.09 \pm 0.03^{\mathrm{B}}$ & $0.68 \pm 0.11^{\mathrm{B}}$ \\
\hline $\mathrm{K}-3$ & $0.00 \pm 0.00^{\mathrm{C}}$ & $0.33 \pm 0.08^{\mathrm{BC}}$ & $5.08 \pm 0.98^{\mathrm{BC}}$ & $0.08 \pm 0.08^{\mathrm{ABC}}$ & $0.15 \pm 0.02^{\mathrm{BC}}$ & $0.01 \pm 0.01^{\mathrm{C}}$ & $0.41 \pm 0.07^{\mathrm{C}}$ \\
\hline $\mathrm{K}-4$ & $0.00 \pm 0.00^{\mathrm{C}}$ & $0.24 \pm 0.04^{\mathrm{C}}$ & $4.34 \pm 0.68^{C}$ & $0.04 \pm 0.00^{\mathrm{C}}$ & $0.57 \pm 0.08^{\mathrm{A}}$ & $0.47 \pm 0.09^{\mathrm{A}}$ & $1.90 \pm 0.29^{\mathrm{A}}$ \\
\hline $\mathrm{K}-5$ & $0.00 \pm 0.00^{\mathrm{C}}$ & $0.41 \pm 0.02^{\mathrm{AB}}$ & $5.23 \pm 0.31^{\mathrm{BC}}$ & $0.10 \pm 0.01^{\mathrm{AB}}$ & $0.15 \pm 0.00^{\mathrm{BC}}$ & $0.03 \pm 0.00^{\mathrm{C}}$ & $0.47 \pm 0.02^{\mathrm{C}}$ \\
\hline K & $0.01 \pm 0.02$ & $0.40 \pm 0.12$ & $5.53 \pm 1.22$ & $0.09 \pm 0.04$ & $0.24 \pm 0.17$ & $0.12 \pm 0.19$ & $0.77 \pm 0.61$ \\
\hline C-1 & $0.00 \pm 0.00^{\mathrm{C}}$ & $0.40 \pm 0.08^{\mathrm{B}}$ & $4.14 \pm 0.76^{\mathrm{C}}$ & $0.06 \pm 0.01^{\mathrm{BC}}$ & $0.07 \pm 0.00^{\mathrm{D}}$ & $0.00 \pm 0.00^{\mathrm{C}}$ & $0.19 \pm 0.02^{\mathrm{DE}}$ \\
\hline $\mathrm{C}-2$ & $0.02 \pm 0.01^{\mathrm{AB}}$ & $0.43 \pm 0.13^{\mathrm{AB}}$ & $4.13 \pm 0.12^{C}$ & $0.07 \pm 0.02^{\mathrm{ABC}}$ & $0.07 \pm 0.00^{\mathrm{D}}$ & $0.00 \pm 0.00^{\mathrm{C}}$ & $0.16 \pm 0.03^{\mathrm{E}}$ \\
\hline $\mathrm{C}-3$ & $0.01 \pm 0.01^{\mathrm{BC}}$ & $0.41 \pm 0.06^{\mathrm{AB}}$ & $5.00 \pm 0.62^{\mathrm{BC}}$ & $0.07 \pm 0.02^{\mathrm{ABC}}$ & $0.10 \pm 0.04^{\mathrm{CD}}$ & $0.00 \pm 0.00^{\mathrm{C}}$ & $0.14 \pm 0.01^{\mathrm{E}}$ \\
\hline $\mathrm{C}$ & $0.01 \pm 0.01$ & $0.41 \pm 0.08$ & $4.42 \pm 0.66$ & $0.07 \pm 0.02$ & $0.08 \pm 0.02$ & $0.00 \pm 0.00$ & $0.17 \pm 0.03$ \\
\hline
\end{tabular}

Means followed by the same superscript letters (A-E) within the column are not significantly different $(p<0.05)$

${ }^{a} \mathrm{~K}-1$, Bonghwa; K-2, Gochang; K-3, Jangheung; K-4, Pohang; K-5, Yeongyang

\section{References}

1. Zhou L, Zuo Z, Chow MSS (2005) Danshen: An overview of its chemistry, pharmacology, pharmacokinetics, and clinical use. J Clin Pharmacol 45: 1345-1359

2. Chae HJ, Chae SW, Yun DH, Keum KS, Yoo SK, Kim HR (2004) Prevention of bone loss in ovariectomized rats: The effect of salvia miltiorrhiza extracts. Immunopharm Immunot 26: 135-144

3. Liu B, Du Y, Cong L, Jia X, Yang G (2016) Danshen (salvia miltiorrhiza) compounds improve the biochemical indices of the patients with coronary heart disease. Evid-Based Compl Alt 2016: 9

4. Liu J, Shen HM, Ong CN (2000) Salvia miltiorrhiza inhibits cell growth and induces apoptosis in human hepatoma HepG2 cells. Cancer Lett 153: 85-93

5. Ji XY, Tan BKH, Zhu YC, Linz W, Zhu YZ (2003) Comparison of cardioprotective effects using ramipril and danshen for the treatment of acute myocardial infarction in rats. Life Sci 73: 1413-1426

6. Choi MS, Cho Dl, Choi HK, Im SY, Ryu SY, Kim KM (2004) Molecular mechanisms of inhibitory activities of tanshinones on lipopolysaccharidelnduced nitric oxide generation in RAW 264.7 cells. Arch Pharm Res 27: 1233-1237

7. Mok JS, Park UY, Kim YM, Chang DS (1994) Effects of solvents and extracting condition on the antimicrobial activity of salviae miltiorrhizae Radix (salvia miltiorrhiza) extract. J Korean Soc Food Sci Nutr 23: 1001-1007

8. Fugh-Berman A (2000) Herbs and dietary supplements in the prevention and treatment of cardiovascular disease. Prev Cardiol 3: 24-32

9. Kang BY, Chung SW, Kim SH, Ryu SY, Kim TS (2000) Inhibition of interleukin-12 and interferon- production in immune cells by tanshinones from salvia miltiorrhiza. Immunopharmacology 49: 355-361

10. Yang SA, Im NK, Lee IS (2007) Effects of methanolic extract from salvia miltiorrhiza Bunge on in vitro antithrombotic and antioxidative activities. Korean J Food Sci Technol 39: 83-87

11. Pan X, Niu G, Liu H (2001) Microwave-assisted extraction of tanshinones from salvia miltiorrhiza Bunge with analysis by highperformance liquid chromatography. J Chromatogr A 922: 371-375

12. Chen AJ, Zhang JY, Li CH, Chen XF, Hu ZD, Chen XG (2004) Separation and determination of active components in Radix Salviae Miltiorrhizae and its medicinal preparations by nonaqueous capillary electrophoresis. J Sep Sci 27: 569-575

13. Hu P, Luo GA, Zhao ZZ, Jiang ZH (2005) Quantitative determination of four diterpenoids in Radix Salviae Miltiorrhizae using LC-MS-MS. Chem Pharm Bull 53: 705-709

14. Duda-Chodak A, Tarko T, Tuszyski T (2011) Antioxidant activity of apples-an impact of maturity stage and fruit part. Acta Sci Pol Technol
Aliment 10: 443-454

15. Ma Z, Guo D, Xu X, Lu M, Bardgett RD, Eissenstat DM, McCormack ML, Hedin LO (2018) Evolutionary history resolves global organization of root functional traits. Nature 555: 94-97

16. Noh YD, Park HJ, Kim KR, Kim WI, Jung KY, Kim SU, Owens VN, Moon JS, Yun SW, Kim SY, Hong CO (2017) Contrasting effect of phosphate on phytoavailability of arsenic and cadmium in soils supporting medicinal plants. Appl Biol Chem 60: 119-128

17. Renger B, Végh Z, Ferenczi-Fodor K (2011) Validation of thin layer and high performance thin layer chromatographic methods. J Chromatogr A 1218: $2712-2721$

18. Hanrahan G, Lu K (2006) Application of factorial and response surface methodology in modern experimental design and optimization. Crit Rev Anal Chem 36: 141-151

19. Hu P, Liang QL, Luo GA, Zhao ZZ, Jiang ZH (2005) Multi-component HPLC fingerprinting of Radix Salviae Miltiorrhizae and its LC-MS-MS identification. Chem Pharm Bull 53: 677-683

20. Chen X, Deng Y, Xue Y, Liang J (2012) Screening of bioactive compounds in Radix Salviae Miltiorrhizae with liposomes and cell membranes using HPLC. J Pharm Biomed Anal 70: 194-201

21. Zhao Q, Song Z, Fang X, Pan Y, Guo L, Liu T, Wang J (2016) Effect of genotype and environment on salvia miltiorrhiza roots using LC/MSbased metabolomics. Molecules 21: 414

22. Cao JL, Wei JC, Hu YJ, He CW, Chen MW, Wan JB, Li P (2016) Qualitative and quantitative characterization of phenolic and diterpenoid constituents in danshen (salvia miltiorrhiza) by comprehensive twodimensional liquid chromatography coupled with hybrid linear ion trap orbitrap mass. J Chromatogr A 1427: 79-89

23. Oarowski M, Piasecka A, Gryszczyska A, Sawikowska A, Pietrowiak A, Opala B, Mikoajczak P, Kujawski R, Kachlicki P, Buchwald W, Seremak-Mrozikiewicz A (2017) Determination of phenolic compounds and diterpenes in roots of salvia miltiorrhiza and salvia przewalskii by two LC-MS tools: Multi-stage and high resolution tandem mass spectrometry with assessment of antioxidant capacity. Phytochem Lett 20: $331-338$

24. Cao JL, Wang SS, Hu H, He CW, Wan JB, Su HX, Wang YT, Li P (2018) Online comprehensive two-dimensional hydrophilic interaction chromatography $\times$ reversed-phase liquid chromatography coupled with hybrid linear ion trap orbitrap mass spectrometry for the analysis of phenolic acids in salvia miltiorrhiza. J Chromatogr A 1536: 216-227

25. Kan S, Chen Z, Shao L, Li Ja (2014) Transformation of salvianolic acid $\mathrm{B}$ to salvianolic acid $\mathrm{A}$ in aqueous solution and the in vitro liver protective effect of the main products. J Food Sci 79: c499-c504

26. Xia H, Sun L, Lou H, Rahman MM (2014) Conversion of salvianolic acid B into salvianolic acid A in tissues of Radix Salviae Miltiorrhizae 
using high temperature, high pressure and high humidity. Phytomedicine 21: 906-911

27. Lee HJ, Cho JY, Moon JH (2012) Chemical conversions of salvianolic acid B by decoction in aqueous solution. Fitoterapia 83: 1196-1204

28. Guo YX, Zhang L, Lu L, Liu EH, Shi CZ (2016) Effects of ultrasonic processing on degradation of salvianolic acid $\mathrm{B}$ in aqueous solution. J Pharm Biomed Anal 129: 252-259

29. Liu AH, Li L, Xu M, Lin YH, Guo HZ, Guo DA (2006) Simultaneous quantification of six major phenolic acids in the roots of salvia miltiorrhiza and four related traditional chinese medicinal preparations by HPLC-DAD method. J Pharm Biomed Anal 41: 48-56

30. Li XB, Xie XM, Pei WZ, Chen JK, Song Y, Yang H, Zhou TS (2009) Improved LC method for the simultaneous determination of five active components in danshen and its preparations. Chromatographia 69: 543548

31. Li XB, Wang W, Zhou GJ, Li Y, Xie XM, Zhou TS (2012) Production of salvianolic acid B in roots of salvia miltiorrhiza (danshen) during the post-harvest drying process. Molecules 17: 2388-2407 